06

\title{
Влияние температуры спекания на формирование сегнетоэлектрических свойств керамики цирконата-титаната свинца
}

\author{
( Е.В. Барабанова, А.А. Топчиев, О.В. Малышкина \\ Тверской государственный университет, \\ Тверь, Россия \\ E-mail: pechenkin_kat@mail.ru \\ (Поступила в Редакцию 16 октября 2017 г.)
}

Исследовалось влияние температуры спекания на формирование микроструктуры, доменной структуры и сегнетоэлектрических свойств пьезокерамики системы цирконата-титаната свинца $\left.\mathrm{Pb}_{\left(\mathrm{T}_{x}\right.} \mathrm{Zr}_{1-x}\right) \mathrm{O}_{3}$. Показано, что формирование сегнетоэлектрической фазы происходит при температуре спекания $860^{\circ} \mathrm{C}$. При дальнейшем увеличении температуры спекания основное влияние на свойства оказывают деформация элементарной ячейки и свободные носители зарядов.

Работа выполнена в Центре коллективного пользования Тверского государственного университета при финансовой поддержке Министерства образования и науки Российской Федерации № 3.8032.2017/БЧ.

DOI: 10.21883/FTT.2018.04.45686.291

\section{1. Введение}

Сегнетоэлектрическая керамика системы цирконататитаната свинца (ЦТС) широко применяется в различных областях промышленности [1-5]. Поскольку условия, в которых эксплуатируются пьезокерамические изделия в различных устройствах и приборах, отличаются большим разнообразием и сложностью, то соответственно модифицируются и физические свойства пьезокерамики. Свойства пьезокерамики на основе твердых растворов цирконата-титаната свинца $\mathrm{Pb}\left(\mathrm{Ti}_{x} \mathrm{Zr}_{1-x}\right) \mathrm{O}_{3}$ существенно зависят как от соотношения $\mathrm{Ti} / \mathrm{Zr}$, так и от наличия в ней ионов других элементов, называемых модификаторами, специально вводимых как добавки.

Поскольку основная фаза керамики на основе цирконата-титаната свинца состоит из кристаллитов твердых растворов со структурой перовскита, с технологической точки зрения она имеет сильно выраженную зависимость собственных параметров не только от состава, но и от технологии получения. Одной из важных технологических операций, влияющей на свойства, является операция спекания. Изменяя температуру спекания и время выдержки, можно отследить этапы формирования структуры (кристаллической, доменной, зерновой) и свойств керамики и их взаимосвязь $[6,7]$.

\section{2. Объекты и методы исследования}

В данной работе в качестве объектов исследования была выбрана пьезоэлектрическая керамика состава ЦТС-46 с пониженной температурой спекания. Данная модификация основана на системе цирконата-титаната свинца вблизи морфотропной фазовой границы, дополнительно содержащей оксиды стронция, вольфрама, висмута, никеля, кадмия. Образцы имели форму дисков диаметром $16 \mathrm{~mm}$ и толщиной $2 \mathrm{~mm}$. Согласно технологическому процессу спрессованные заготовки керамики ЦТС-46 спекаются при температуре $970^{\circ} \mathrm{C}$ с выдержкой $4 \mathrm{~h}$. Для изучения влияния температуры спекания на формируемые свойства производился обжиг керамики в муфельной печи при температурах 860, 890, 910, 930, 950 и $970^{\circ} \mathrm{C}$. Скорость нагрева и время выдержки оставались неизменными. В качестве минимальной температуры обжига была выбрана температура $860^{\circ} \mathrm{C}$, поскольку, как было показано ранее [8], начиная с данной температуры в керамике происходит активное увеличение размеров зерен, и у образцов, спеченных при данной температуре, наблюдается доменная структура, что свидетельствует о наличии сегнетоэлектрических свойств.

Исследование микроструктуры и доменной структуры спеченной керамики производилось на атомно-силовом микроскопе (ACM) фирмы NT-MDT в режиме силовой микроскопии пьезоотклика (СМП). Исследование элементного состава образцов проводилось на растровом электронном микроскопе (PЭМ) JEOL JSM 6610 LV, оснащенном системой энергодисперсионного анализа Oxford INCA Energy 350, в режиме вторичных электронов. Диэлектрические характеристики измерялись при комнатной температуре в диапазоне частот $10-10^{6} \mathrm{~Hz}$ с помощью фазочувствительного измерителя Вектор175. Наблюдение петель диэлектрического гистерезиса проводилось по методу Сойера-Тауэра при комнатной температуре. Для измерения пьезомодуля применялся метод резонанса-антирезонанса.

\section{3. Экспериментальные результаты и их обсуждение}

Домены, формируемые при спекании образцов керамики ЦТС-46 при температуре $860^{\circ} \mathrm{C}$, имеют неправильную форму с нечеткими границами раздела (рис. 1,a). 

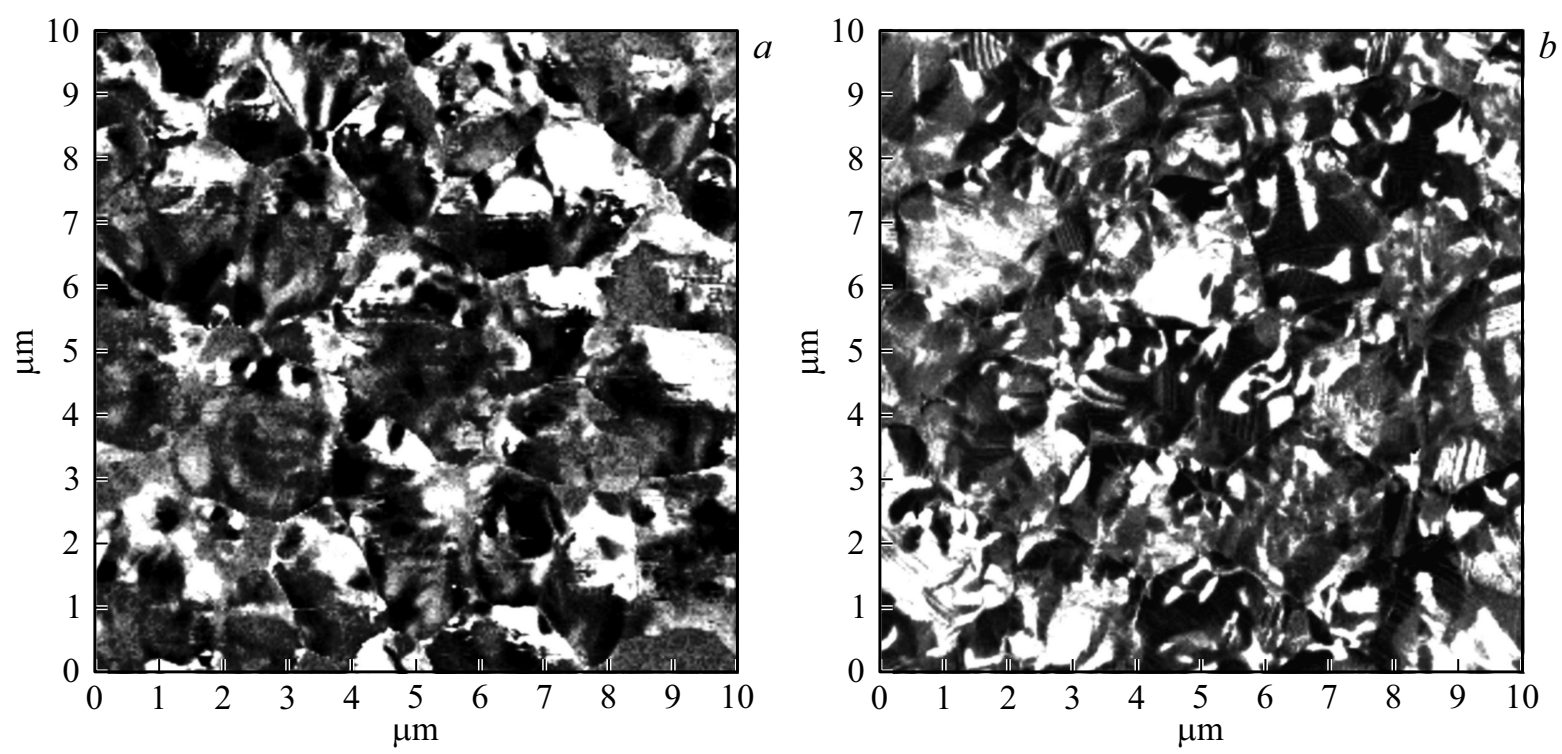

Рис. 1. СМП изображения доменной структуры образцов ЦТС-46, синтезированных при температуре $860(a)$ и $890^{\circ} \mathrm{C}(b)$. Размер области сканирования $10 \times 10 \mu \mathrm{m}$.

При повышении температуры спекания до $890^{\circ} \mathrm{C}$ появляются полосовые домены. Размер их в среднем составляет порядка 100-200 nm (рис. 1, b). Согласно литературным данным [9-12], у кристаллов, находящихся в тетрагональной фазе, могут существовать домены со 180- и 90-градусными доменными границами. Как известно, система керамики ЦТС вблизи морфотропной границы [5] находится в тетрагональной фазе. Таким образом, наблюдаемые различные формы доменной структуры, по всей видимости, имеют разные доменные границы.

Согласно литературным данным [13], размер доменов пропорционален размеру зерен в степени 0.5. Проведенные исследования показали, что при увеличении температуры спекания выше $890^{\circ} \mathrm{C}$ изменений доменной

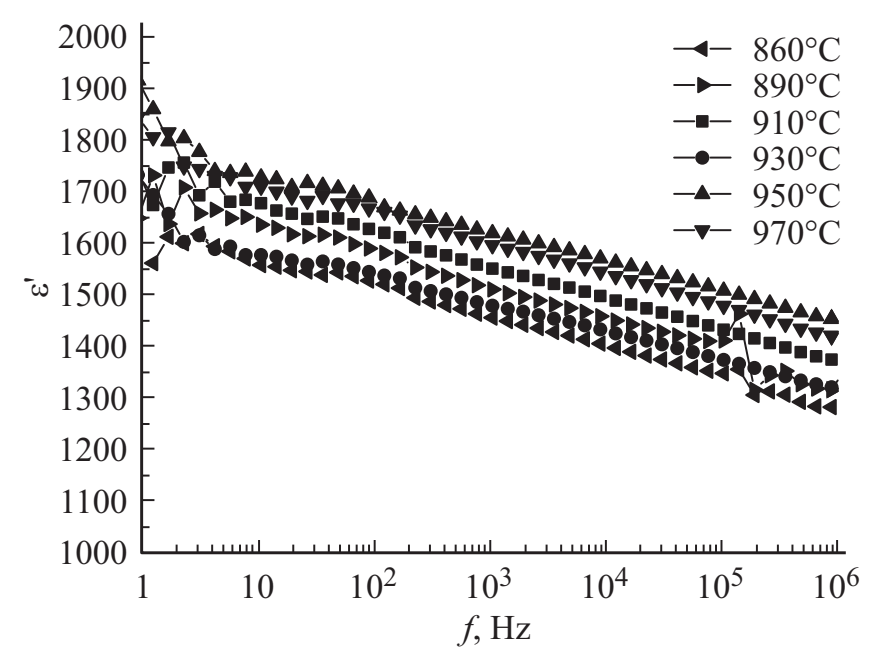

Pис. 2. Частотная зависимость действительной части диэлектрической проницаемости в логарифмическом масштабе для образцов, спеченных при различных температурах.

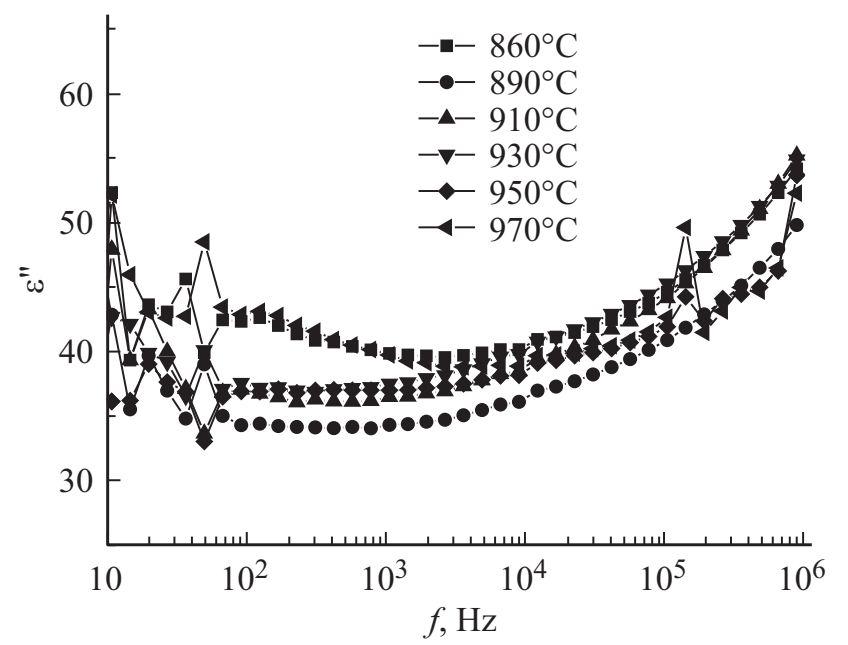

Рис. 3. Частотная зависимость мнимой части диэлектрической проницаемости в логарифмическом масштабе для образцов, спеченных при различных температурах.

структуры не наблюдается, тогда как увеличение размера зерен продолжается.

Исследования частотной зависимости комплексной диэлектрической проницаемости образцов, спеченных при различных температурах (рис. 2), показали, что величина диэлектрической проницаемости незначительно меняется в зависимости от температуры, при которой происходило спекание керамики. Для всех образцов наблюдается монотонное уменьшение $\varepsilon^{\prime}$ (рис. 2) и увеличение диэлектрических потерь $\varepsilon^{\prime \prime}$ (рис. 3) с ростом частоты. Закономерности в изменении величины диэлектрических потерь от температуры спекания образца также не выявлено. 
Стоит отметить, что частотная зависимость диэлектрической проницаемости в области высоких частот при температурах спекания 860 и $890^{\circ} \mathrm{C}$ имеет вид резонансной дисперсии: с ростом частоты $\varepsilon^{\prime}$ проходит последовательно через максимум и минимум, а $\varepsilon^{\prime \prime}$ имеет точку максимума (рис. 2,3). Время релаксации данного поляризационного процесса, рассчитанное по частоте, соответствующей максиму на частотной зависимости $\mathcal{\varepsilon}^{\prime}(f)$, для обеих температур спекания составило $1.1 \mu \mathrm{s}$. Данное время релаксации значительно превосходит времена релаксации, характерные для механизмов упругой поляризации, которым свойственна резонансная дисперсия, так как они проявляются на частотах более $10^{10} \mathrm{~Hz}[14]$.

Причиной резонансной дисперсии может являться также электромеханический (пьезоэлектрический) вклад в диэлектрическую проницаемость. Но он характерен для полярных материалов, т.е. обладающих полярной осью, вдоль которой направлен вектор поляризации. Если сегнетокерамика не поляризована, то считается, что векторы поляризации отдельных доменов внутри материала направлены хаотически и в сумме дают нуль [15]. Наличие электромеханического вклада у неполяризованной керамики может говорить о том, что по своей природе данная керамика является униполярной, т.е. в неполяризованном состоянии обладает ненулевой макроскопической спонтанной поляризацией. Это подтверждают данные по исследованию пироотклика керамики: образцы, спеченные при всех температурах, кроме температуры $970^{\circ} \mathrm{C}$, имеют слабый сигнал пиротока. Кроме того, в неполяризованной керамике можно наблюдать пьезорезонанс. Частоты резонанса-антирезонанса примерно совпадают с частотами, на которых наблюдается резонансная дисперсия диэлектрической проницаемости (рис. 2).

Петли диэлектрического гистерезиса исследовались в переменном электрическом поле напряженностью $587 \mathrm{~V} \cdot \mathrm{mm}^{-1}$. После помещения образцов в электрическое поле наблюдалась формовка петли диэлектрического гистерезиса. Сформированные петли имели сильно вытянутую вдоль оси $X$ форму. После достижения максимального раскрытия петель в образцах резко возрастала проводимость, о чем свидетельствовало изменение формы петли - переход в эллипс потерь. Максимальное значение остаточной поляризации составляло $0.037,0.030,0.040,0.060,0.050,0.094 \mathrm{C} \cdot \mathrm{m}^{-2}$ у образцов, спеченных при температурах 860, 890, 910, 930, 950 и $970^{\circ} \mathrm{C}$ соответственно. Величина коэрцитивного поля во всех случаях одинакова $\left(170 \mathrm{~V} \cdot \mathrm{mm}^{-1}\right)$. Независимость величины коэрцитивного поля от температуры спекания говорит о том, что на переключение доменов требуется во всех случаях одна и та же энергия, это согласуется с наблюдаемой доменной структурой. Так, согласно [16], коэрцитивное поле обратно пропорционально зависит от количества типов доменной структуры в материале. Вероятно, наблюдаемые на АCM во всех образцах полосовые домены и домены неправильной формы соответствуют двум основным типам доменов,

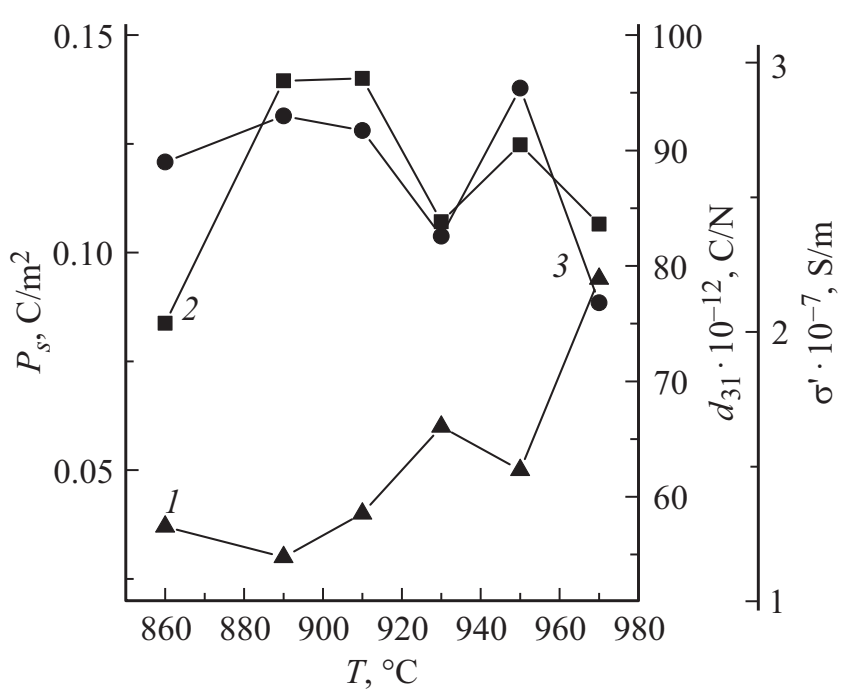

Рис. 4. Зависимость остаточной поляризации $P_{s}(1)$, удельной проводимости $\sigma^{\prime}(2)$ и пьезомодуля $d_{31}(3)$ от температуры спекания керамики ЦТС.

существующим в образцах ЦТС, находящихся в тетрагональной фазе, - 180- и 90-градусным доменам.

Изменение остаточной поляризации с изменением температуры спекания образцов свидетельствует о наличии механизмов экранирования поляризации свободными носителями при спекании на низких температурах. Так, на рис. 4 уменьшению поляризации соответствует рост проводимости и наоборот.

Величина пьезомодуля $d_{31}$ при увеличении температуры спекания изменяется обратно пропорционально величине поляризации (рис. 4). В этом случае механические напряжения в направлении перпендикулярном вектору поляризации, должны быть пропорциональны его модулю. Таким образом, увеличение поляризации говорит не только об уменьшении проводимости, но и о росте механических напряжений в плоскости образца. Это в свою очередь приводит к значительным деформациям керамики при спекании на высоких температурах (выше $950^{\circ} \mathrm{C}$ ).

\section{4. Заключение}

На основании проведенных исследований можно сделать следующие выводы. Увеличение температуры спекания пьезоэлектрической керамики ЦТС-46 приводит к увеличению среднего размера зерен, но не оказывает существенного влияния на диэлектрические свойства керамики. Доменная структура формируется в узком интервале температур спекания в два этапа: сначала домены неправильной формы, затем полосовые, число и размер которых не зависят от дальнейшего увеличения температуры спекания.

Максимальная проводимость наблюдается при температурах $890-910^{\circ} \mathrm{C}$. Согласно [5], начиная с температуры спекания $860^{\circ} \mathrm{C}$ интенсивно протекают твердофазные реакции, сопровождаемые выгоранием связки, что, 
возможно, и приводит к росту проводимости. Ранние исследования структуры и элементного состава на РЭМ показали [8], что при температурах спекания до $910^{\circ} \mathrm{C}$ на поверхности образцов можно наблюдать „спеки“, химический состав которых существенно отличается от состава основной матрицы. Это означает, что помимо процесса синтеза протекает процесс выгорания элементов, не участвующих в создании кристаллической решетки керамики ЦТС-46. Далее, при увеличении температуры спекания, концентрация непрореагировавших ионов уменьшается и происходит уменьшение проводимости и рост поляризации. Увеличение поляризации с увеличением температуры спекания происходит более интенсивно, чем уменьшение проводимости. Следовательно, на величину поляризации оказывает влияние не только экранирование свободными зарядами, но и процессы, происходящие внутри доменов. К росту поляризации может приводить увеличение деформации элементарной ячейки, т.е. величины дипольных моментов. В пользу такого вывода говорит зависимость пьезомодуля $d_{31}$ от температуры спекания.

\section{Список литературы}

[1] D619: Piezoelectric Materials — Global Technology Developments. www.frost.com

[2] B.L. Gupta, T. Abraham. ET-102 Piezoelectric Operated Actuators and Motors - A Global Industry and Market Analysis. Innovative Research and Products, Inc., Stamford (2006). 111 p.

[3] E. Gusev, E. Garfunkel, A. Dideikin. Advanced Materials and Technologies for Micro/Nano-Devices, Sensors and Actuators. NATO Science for Peace and Security Series - B: Physics and Biophysics. Springer Verlag, Germany (2010). 313 p.

[4] S.B. Choi, Y.M. Han. Piezoelectric Actuators: Control Applications of Smart Materials. CRC Press, N.Y. (2010). 280 p.

[5] В.А. Головнин, И.А. Каплунов, О.В. Малышкина, Б.Б. Педько, А.А. Мовчикова. Физические основы, методы исследования и практическое применение пьезоматериалов. Техносфера, М. (2013). 272 с.

[6] Г.М. Константинов, М.Ф. Куприянов, Б.Г. Корницкий, А.Е. Панич, Ю.С. Дудек. ЖТФ 60, 109 (1990).

[7] А.М. Антоненко, А.Ю. Кудзин, М.Г. Гавшин. ФТТ 39, 920 (1997).

[8] O.V. Malyshkina, E.V. Barabanova, A.I. Ivanova, A.V. Daineko, V.A. Golovnin. Ferroelectrics 475, 82 (2015).

[9] C.A. Randall, D.J. Barber, R.W. Whatmore. J. Mater. Sci. 22, 925 (1987).

[10] S. Dunn, C.P. Shaw, Z. Huang, R.W. Whatmore. Nanotechno$\operatorname{logy} 13,456(2001)$.

[11] P.R. Potnis, N.-T. Tsou, J.E. Huber. Materials 4, 417 (2011).

[12] И.С. Желудев. Физика кристаллических диэлектриков. Наука, М. (1968). 464 c.

[13] W. Cao, C.A. Randall. J. Phys. Chem. Solids 57, 1499 (1996).

[14] Ю.М. Поплавко, Л.П. Переверзева, И.П. Раевский. Физика активных диэлектриков. Изд-во Южного федерального унта. Ростов н/Д. (2009). 480 с.

[15] К. Окадзаки. Технология керамических диэлектриков. Пер. с яп. Энергия, М. (1976). 336 с.

[16] S. Choudhury, L.Q. Chen, Y.L. Li. Appl. Phys. Lett. 91, 032902:1 (2007). 